\title{
Complete Second Branchial Fistula: Diagnostic Imaging and Surgical Aspects
}

\author{
${ }^{1}$ Sampan S Bist, ${ }^{2}$ Kartikya Purohit, ${ }^{3}$ Vinish Agarwal, ${ }^{4}$ Bhartendu Bharti, ${ }^{5}$ day Monga
}

\begin{abstract}
Introduction: Complete branchial fistulae are rare anomalies of the branchial cleft apparatus. Incomplete fistulae occur more commonly and may be completely asymptomatic. They are often neglected as they do not lead to recurrent infection, while complete branchial fistula have persistent symptom of discharge. The branchial fistula very rarely has two openings. Usually, a thin membrane covering the internal opening is present even if both ends are patent. Demonstration of a complete branchial fistula on imaging studies is also very uncommon. This is a study of five cases of complete second branchial fistulae, which were diagnosed and treated surgically in a tertiary care teaching hospital over a period of 3 years. The case study also make special emphasis on preoperative imaging for the confirmation of diagnosis and for appropriate surgical approach for complete excision of fistulous tract in order to minimize the recurrence as the revision second-look surgery in neck region is usually difficult.
\end{abstract}

Keywords: Complete branchial fistula, Imaging, Surgical aspects.

How to cite this article: Bist SS, Purohit K, Agarwal V, Bharti B, Monga U. Complete Second Branchial Fistula: Diagnostic Imaging and Surgical Aspects. Int J Otorhinolaryngol Clin 2016;8(1):6-10.

\section{Source of support: Nil \\ Conflict of interest: None}

\section{INTRODUCTION}

Branchial fistulas are uncommon anomalies of embryonic development of branchial apparatus, which consists of five mesodermal arches separated by invaginations of the ectoderm called as clefts. During the embryonic development, the second arch grows caudally; envelops the third, fourth, and sixth arches; and forms the cervical sinus by fusing with the skin caudal to these arches. The ectoderm inside the fused tube disappears, while the edges of cervical sinus fuse. Branchial cyst occurs due to persistence of ectoderm. The breakdown of the endoderm,

${ }^{1}$ Professor and Head, ${ }^{2,5}$ Postgraduate Student, ${ }^{3,4}$ Assistant Professor

${ }^{1-5}$ Department of ENT, Himalayan Institute of Medical Sciences Dehradun, Uttarakhand, India

Corresponding Author: Sampan S Bist, Professor and Head Department of ENT, Himalayan Institute of Medical Sciences Dehradun, Uttarakhand, India, Phone: +919411192856, e-mail: sampanbist@yahoo.com usually in the second pouch, results in branchial fistula. The second branchial cleft and pouch fistula pass from the external opening in the mid or lower one-third of the neck at the anterior border of the sternocleidomastoid muscle, deep to the platysma along the carotid sheath, then pass medially deep between the internal and external carotid arteries after crossing over the glossopharyngeal nerve and hypoglossal nerve. Finally, it opens internally either on the anterior face of the upper half of the posterior pillar of the fauces or in the intratonsillar cleft in the tonsillar fossa. ${ }^{1}$ Because of this anatomical route, these long tubular structures are intimately associated with major neurovascular structures in the neck. Most often, it is a simple sinus opening that extends up the neck for a variable distance. Ninety percent of the developmental abnormalities of the branchial apparatus are attributed to anomalies of the second branchial cleft. ${ }^{2}$ However, complete second arch fistula with internal opening into the tonsillar region is rare and comprises $2 \%$ of all branchial anomalies. ${ }^{3}$ Although branchial fistulas may occur in any age group, commonly, patients present to a clinician in first and second decades of life. ${ }^{4}$ Persistent mucoid discharge from a fistula opening or infection in the lower part of neck with mucopurulent discharge is the most common presenting symptoms in these patients. ${ }^{3}$ The completeness of fistula can be diagnosed by a dye test or fistulogram, and sometimes negative preoperative test might become positive under general anesthesia because of muscle relaxation. ${ }^{1}$ Occasionally, thick secretions or granulation tissue may obstruct the fistula tract. ${ }^{4}$ This case series of five patients having complete second branchial cleft fistula emphasizes the need for preoperative imaging and appropriate surgical approach to safeguard the major neurovascular structures in the neck and recurrence.

\section{MATERIALS AND METHODS}

This study was carried out in the Department of Otorhinolaryngology in a tertiary care teaching hospital. A total of five cases diagnosed as complete second branchial fistula in the past 3-year period were included in this study. Patients with a history of previous neck surgeries and neck trauma were excluded from the study. In all the cases, complete history and clinical findings were recorded. On the basis of clinical examination and symptoms, they were diagnosed as branchial 
sinus/fistula. A preoperative sinogram/fistulogram was done in all the cases to reveal the extent of the tract. After necessary routine investigations to confirm the surgical fitness, excision of the tract was carried out via combined transcervical and transoral approach under general anesthesia. Intraoperatively, Methylene blue dye was injected through the external opening, and in three patients dye spill in oropharynx was observed on pharyngoscopy, while in two there was staining in the tonsillar fossa. Initially, circumscribed incision was taken around the fistulous opening. Then the fistulous tract was separated from the skin and fascia over it. A second incision (stepladder dissection) was taken in the upper part of the neck at the level of the hyoid bone over the anterior border of the sternocleidomastoid and the tract was delivered upward through the incision and the dissection was carried further toward the oropharynx. The relationship with carotid vessels was observed and meticulous dissection was carried out along the tract. Complete excision was possible by gentle traction on the tract and cord-like tract could be followed up to the tonsillar fossa. Confirmed attachment with tonsilar fossa and tonsil with fistulous tract was excised along with it and sent for histopathological evaluation.

\section{OBSERVATIONS}

Five cases were diagnosed as complete second branchial cleft fistula in the span of 3 years. The age range was from 6 to 17 years with male: Female ratio being 4:1 and right: Left ratio being 5:0. Four patients presented in the second decade, while one present in the first decade of life. Rural urban population ratio was 3:2. All patients belonged to middle socioeconomic class. No positive family history was found in any case and there was no involvement of other family member for any branchial anomalies. There

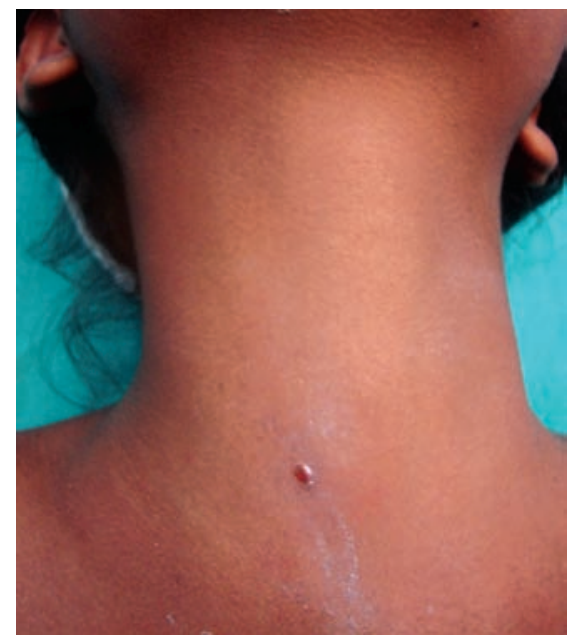

Fig. 1: Sinus opening with active mucopurulent discharge

were no other congenital anomalies in any case. In three cases, parents noticed the opening in the neck in the first year of life, while in two cases it was noticed after the child's first birthday. In four cases, parents consulted the local doctor for this problem after noticing the opening in the neck, while in one case the first consultation was in our hospital. All these cases had history of intermittent discharge from the opening in the lower part of neck and none of them had any complaints of discharge in oropharynx. Examination of oropharynx did not reveal any visible opening or swelling in the pharynx in any case. On neck examination, small opening was present at the junction of upper two-thirds and lower one-third of anterior border of sternocleidomastoid muscle in all the cases (Fig. 1). Patients presenting with mucoprulent discharge were given a course of antibiotics before advising sinogram. On the basis of history, clinical examination, and preoperative sinogram/fistulogram, they were diagnosed as complete branchial fistula (Figs 2A and B).
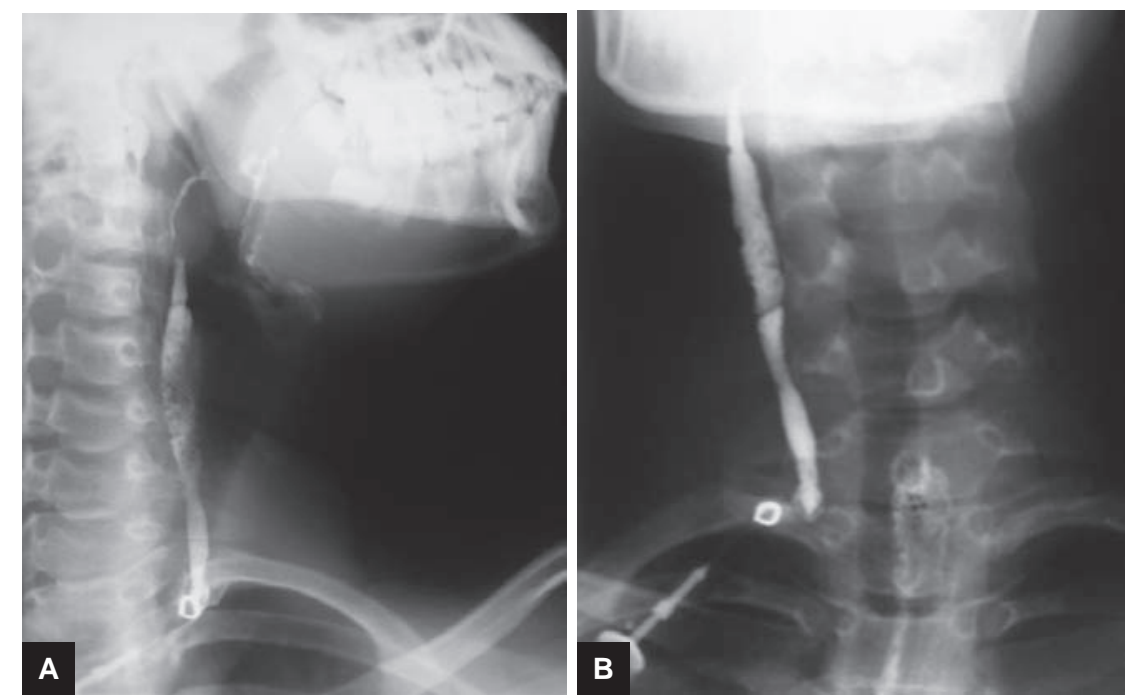

Figs $2 A$ and B: Sinogram anteroposterior and lateral view showing the tract extending in neck up to the tonsillar region 
It was possible in all cases to remove the fistulous tract with tonsil in total by transcervical and transoral approach (Figs 3 to 6). After complete excision of fistula, the tracts measuring between 8 and $14 \mathrm{~cm}$ in length were sent for histopathological study (Figs 7A to B). Histopathological

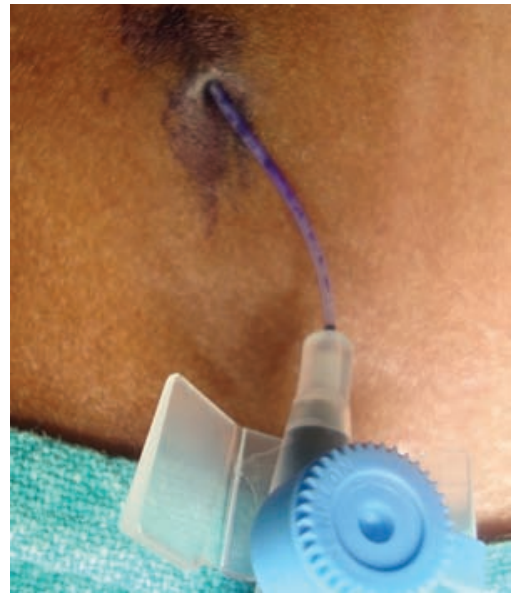

Fig. 3: Intraoperatively methyline blue dye was injected through the external opening

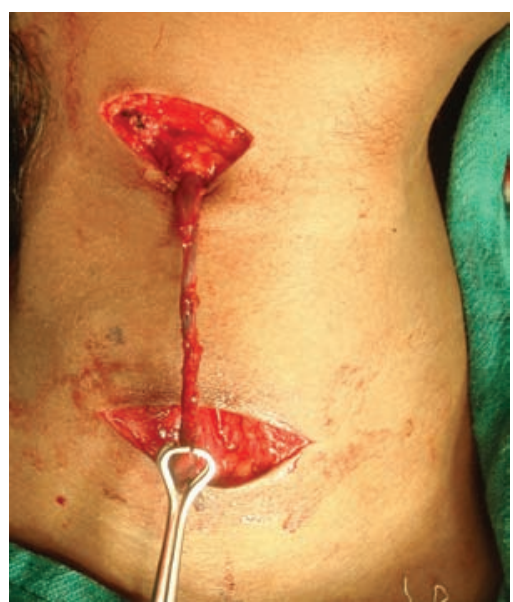

Fig. 5: Transcervical approach (step ladder dissection)

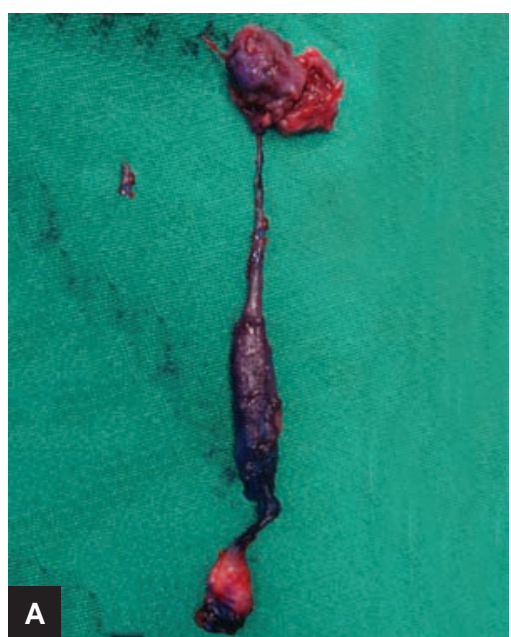

examination was confirmed as the branchial anomalies in all the cases. Postoperative period was uneventful in all the cases and no recurrence was reported in the patients till last follow-up in any case. The patient details are described in Table 1.

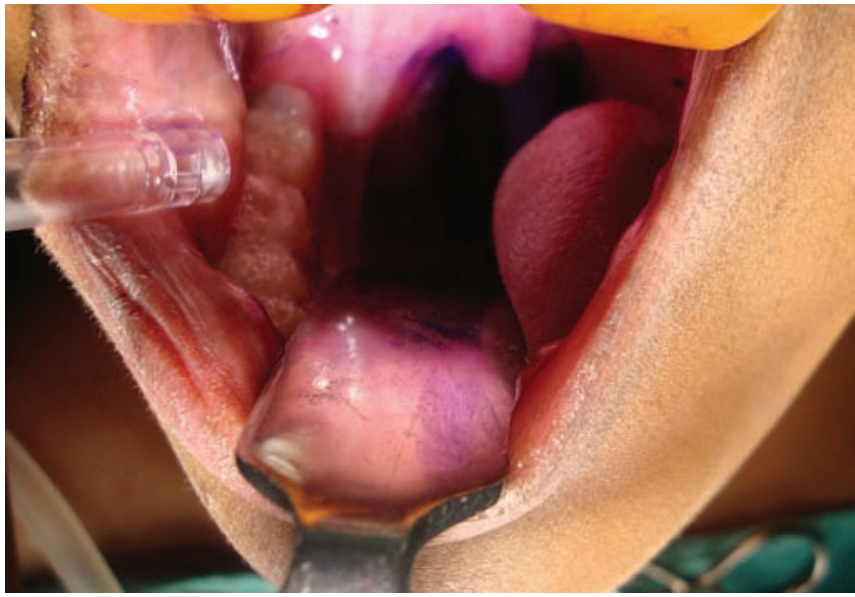

Fig. 4: On pharyngoscopy dye spill in oropharynx with staining in tonsillar fossa

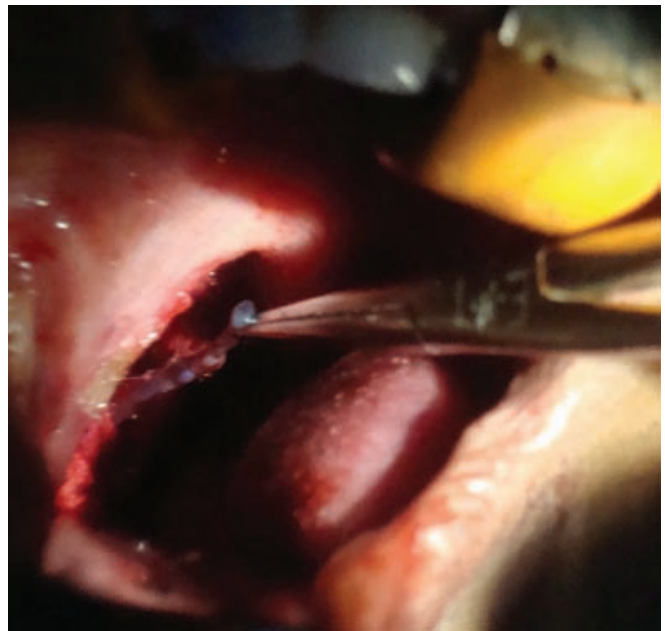

Fig. 6: Excision of fistulous tract with tonsil through transoral approach

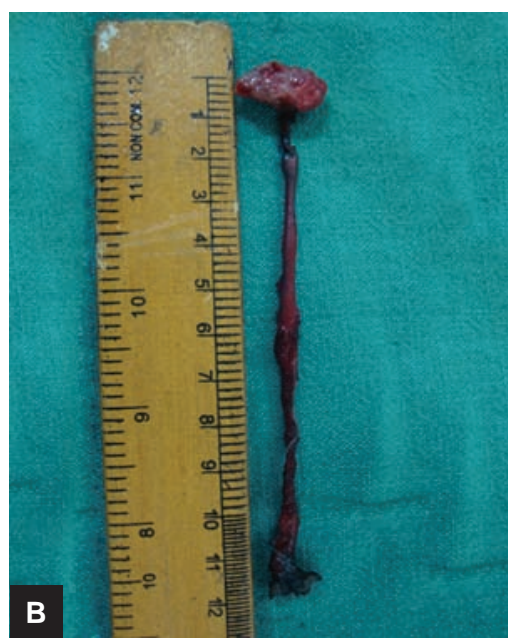

Figs 7A to B: Tonsil with excised fistulous tract 
Table 1: Profile of patients

\begin{tabular}{|c|c|c|c|c|c|c|}
\hline $\begin{array}{l}\text { SI. } \\
\text { no. }\end{array}$ & $\begin{array}{l}\text { Age/ } \\
\text { Sex }\end{array}$ & Clinical presentation & Sinogram & Surgical approach & Internal opening & Follow-up \\
\hline 1 & $11 / \mathrm{M}$ & $\begin{array}{l}\text { Opening in lower } 1 / 3 \text { rd } \\
\text { of neck on right with } \\
\text { intermittent mucoid } \\
\text { discharge }\end{array}$ & $\begin{array}{l}\text { Fistulous tract opening in } \\
\text { the tonsillar fossa }\end{array}$ & $\begin{array}{l}\text { Transcervical and } \\
\text { transoral }\end{array}$ & $\begin{array}{l}\text { Anterior face of the } \\
\text { upper half of the } \\
\text { posterior pillar of the } \\
\text { fauces }\end{array}$ & $\begin{array}{l}2 \text { years } \\
\text { No recurrence }\end{array}$ \\
\hline 2 & $17 / M$ & $\begin{array}{l}\text { Opening in lower } 1 / 3 \text { rd of } \\
\text { neck on right with active } \\
\text { mucopurulent discharge } \\
\text { and inflamed margins } \\
\text { of the sinus opening }\end{array}$ & $\begin{array}{l}\text { Fistulous tract opening in } \\
\text { the tonsillar fossa. During } \\
\text { procedure patient felt the } \\
\text { taste of dye in the mouth }\end{array}$ & $\begin{array}{l}\text { Transcervical and } \\
\text { transoral }\end{array}$ & $\begin{array}{l}\text { In the intratonsillar } \\
\text { cleft }\end{array}$ & $\begin{array}{l}2 \text { years } \\
\text { No recurrence }\end{array}$ \\
\hline 3 & 06/M & $\begin{array}{l}\text { Opening in lower } 1 / 3 \text { rd } \\
\text { of neck on right with } \\
\text { intermittent mucoid } \\
\text { discharge }\end{array}$ & $\begin{array}{l}\text { Blind sinus tract ending in } \\
\text { the tonsillar fossa }\end{array}$ & $\begin{array}{l}\text { Transcervical and } \\
\text { transoral }\end{array}$ & $\begin{array}{l}\text { Anterior face of the } \\
\text { upper half of the } \\
\text { posterior pillar of the } \\
\text { fauces }\end{array}$ & $\begin{array}{l}20 \text { months } \\
\text { No recurrence }\end{array}$ \\
\hline 4 & $15 / M$ & $\begin{array}{l}\text { Opening in lower } 1 / 3 \text { rd of } \\
\text { neck on right with active } \\
\text { mucopurulent discharge } \\
\text { and inflamed margins } \\
\text { of the sinus opening }\end{array}$ & $\begin{array}{l}\text { Fistulous tract opening in } \\
\text { the tonsillar fossa During } \\
\text { procedure patient felt the } \\
\text { taste of dye in the mouth }\end{array}$ & $\begin{array}{l}\text { Transcervical and } \\
\text { transoral }\end{array}$ & $\begin{array}{l}\text { Anterior face of the } \\
\text { upper half of the } \\
\text { posterior pillar of the } \\
\text { fauces }\end{array}$ & $\begin{array}{l}13 \text { months } \\
\text { No recurrence }\end{array}$ \\
\hline 5 & $15 / F$ & $\begin{array}{l}\text { Opening in lower } 1 / 3 \text { rd of } \\
\text { neck on right with active } \\
\text { mucopurulent discharge } \\
\text { and inflamed margins } \\
\text { of the sinus opening }\end{array}$ & $\begin{array}{l}\text { Fistulous tract opening in } \\
\text { the tonsillar fossa During } \\
\text { procedure patient felt the } \\
\text { taste of dye in the mouth } \\
\text { injected }\end{array}$ & $\begin{array}{l}\text { Transcervical and } \\
\text { transoral }\end{array}$ & $\begin{array}{l}\text { In the intratonsillar } \\
\text { cleft }\end{array}$ & $\begin{array}{l}9 \text { months } \\
\text { No recurrence }\end{array}$ \\
\hline
\end{tabular}

\section{DISCUSSION}

Von Baer first described the branchial apparatus, but the anomalies in its development were ascribed by von Ascheron. ${ }^{5}$ Branchial cysts are more common $(80.8 \%)$ than branchial fistulae. ${ }^{6}$ Demonstration of a complete branchial fistula with internal opening into the tonsillar region is rare. Fistulae are present at birth but a majority of times a small pinpoint external opening may go unnoticed. The fistula is more commonly seen in males $(60 \%)$ and 2 to $10 \%$ of them can be bilateral. ${ }^{7}$ When unilateral, $70 \%$ of them occur on the right side; $39 \%$ are complete fistulae, $50 \%$ are external draining sinuses, and $11 \%$ have internal opening alone. ${ }^{3}$ A positive family history of branchial anomalies may be present in 35\% of the patients with complete fistula. ${ }^{3}$ Anatomically, a typical second cleft fistula has its external opening at the anterior border of sternomastoid at the junction of middle and lower one-third. At the upper end, the tract opens in to the posterior tonsillar pillar, supratonsillar fossa, or onto the tonsillar surface. ${ }^{3}$ The length of tract can range from 1 to $8 \mathrm{~cm} .{ }^{7}$ Although branchial fistulas may occur in any age group, commonly patients present to clinician in first and second decades of life. ${ }^{4}$ Symptoms include intermittent or continuous mucous discharge or sometimes mucoprulent and recurrent attacks of inflammation following an attack of upper respiratory tract infection. Occasionally, an incision and drainage may be needed for cellulitis or abscess formation. Sometimes, concurrent anomalies of the first and second arches or conductive or sensory neural deafness may also occur in the patients. ${ }^{3}$ In our study, none of the patients had any other anomalies of first and second arch derivatives. Sometimes, symptoms, such as, cough, palpitation, pallor, and vomiting may occur while probing the tract because of the tract's proximity to the vagus nerve. ${ }^{3}$ We did not not encounter any symptoms on probing in our study. The diagnosis is most often clinical, and radiological investigations are asked for the extent of the tract. The fistulography is an effective method of showing the exact anatomy and topography of these fistulae tract in the neck and it is often the commonest investigation available as done in our cases. This method is painless, simple, and cost-effective. Demonstration of a complete branchial fistula up to the tonsillar region on imaging studies is rare. ${ }^{8}$ Ford et al. ${ }^{3}$ documented one case in their series of 98 fistulae in which the entire tract was visualized. The completeness of fistula can be diagnosed by a dye test or fistulogram and sometimes negative preoperative test might become positive under general anesthesia because of muscle relaxation. ${ }^{1}$ In our study, fistulogram demonstrated complete fistula in three cases, while in two cases it was demonstrated intraoperatively when the dye was injected. Occasionally, thick secretions or granulation tissue may obstruct the fistula tract. ${ }^{4}$ Computed tomography (CT) scan and magnegtic resonance imaging (MRI) of the neck are helpful to produce cross-sectional images of organ and other internal body structures. ${ }^{9}$ They are useful mainly in delineating the relationship of surrounding neurovascular structures to the lesion. Recently, with 
the availability of multislice CT scan, a CT fistulogram with reformatted images unambiguously delineated the relation of sinus tract to that of important structures of neck. ${ }^{10}$ It also helps in classifying the type of lesion, provides a roadmap for surgeon prior to surgery, and reduces the chance of recurrence. Type I first branchial cleft cysts and second branchial cleft cyst manifesting as parapharyngeal mass may be diagnosed by MRI. Surgical excision is the treatment of choice for branchial fistula. In asymptomatic patients, surgery may not be required. However, most of them are symptomatic and the surgical excision is carried out to avoid the risk of recurrent infection and for cosmetic reasons. Nowadays, sclerosing agents are not preferred due to the associated inflammatory reaction and the risk of perforation into the pharynx. ${ }^{2}$ Several surgical approaches have been described for the management of a branchial fistula. These include a transcervical approach, either by a stepladder approach or through a long incision along the anterior border of sternocleidomastoid and a combined pull-through technique. Incisions for the excision could be hockeystick-type ${ }^{11}$ or stepladder incision. ${ }^{12}$ The standard surgery for a second branchial arch fistula is the stepladder approach originally described by Bailey in 1933 with two incisions in the neck that gives exposure of the fistula tract with less tissue dissection. ${ }^{12}$ The higher incision should be bigger than the lower one because the fistula tract is deeper in the vicinity of important neurovascular structures. We have done surgical excision of all five cases by starting with elliptical excision of the fistula opening. Injecting the dye into the opening prior to surgery facilitates the dissection of track. All our patients required further skin incision to avoid injury to the carotid vessel as they were second branchial fistulae. Excision of tonsillar fossa opening was done for continuous removal of tract in 1992, Talaat described another variationpull-through branchial fistulectomy. ${ }^{1}$ In this technique, one or two (stepped) neck incisions are made to dissect the infrahyoid portion of the fistula. Parapharyngeal segment is dissected from the mouth and is continued to the level of the hyoid bone. Then tonsillectomy is performed and the fistula is withdrawn through the mouth. Taylor and Bicknell described the stripping method in 1977. But this has not gained popularity due to the high risk of injury to the adjacent structures. ${ }^{3}$ We have successfully done surgical excision by combined transcervical and transoral approach in all the five cases without any morbidity. Most frequent complication of the surgery is recurrence, occurring in 3\% of fresh cases to up to $20 \%$ in second surgical attempts. However, when only external approach was used, the reported incidence of recurrence rate was $3 \%$. This most probably is due to incomplete excision of the fistula tract in the parapharyngeal space. ${ }^{3}$ However, no recurrence rate is reported after using combined transoral and transcervical approach till now in the English literature. Other complications include secondary infection; injury to facial, hypoglossal, glossopharyngeal, spinal accessory nerves; and injury to internal jugular vein; bad scar; and hematoma formation. ${ }^{11}$

\section{CONCLUSION}

A complete second branchial fistula demonstrable on imaging studies is rare. Imaging studies in the form of a fistulogram confirm the diagnosis, define the extent of the tract, and provide a roadmap for surgeon prior to surgery, which facilitates its complete excision thereby reducing recurrence rates. It is not possible to excise the complete second branchial fistula totally with transcervical approach only. This is a study of complete second branchial fistulae, which were managed through combined approach. Complete branchial fistulae are better managed by otolaryngologists who are familiar with both routes of the combined approach.

\section{REFERENCES}

1. Talaat M. Pull-through branchial fistulectomy: technique for the otolaryngologist. Ann Otol Rhino Laryngol 1992 Jun;101(6):501-502.

2. Burton MG. Second branchial cleft cyst and fistula. Am J Radiol 1980 May;134(5):1067-1069.

3. Ford GR, Balakrishnan A, Evans JN, Bailey CM. Branchial cleft and pouch anomalies. J Laryngol Otol 1992 Feb;106(2):137-143.

4. Ang AH, Pang KP, Tan LK. Complete branchial fistula. Case report and review of the literature. Ann Otol Rhinol Laryngol 2001 Nov;110(11):1077-1079.

5. Ismail Y, Ozcan C, Nuri O, Fatih B, Beyhan D. Complete fistula of the second branchial cleft: case report of catheter aided total excision. Int J Pediatr Otorinolaryngol 2004 Aug;68(8):1109-1113.

6. Shin LK, Gold BM, Zelman WH, Katz DS. Fluoroscopic diagnosis of a second branchial cleft fistula. AJR Am J Roentgenol 2003 Jul;181(1):285.

7. Rattan KN, Rattan S, Parihar D, Gulia JS, Yadav SP. Second branchial cleft fistula. Is fistulogram necessary for total excision? Int J Pediatr Otorhinolaryngol 2006 Jun;70 (6):1027-1030.

8. Augustine AJ, Pai KR, Govindarajan R. Clinics in diagnostic imaging. Sing Med J 2001 Oct;42(10):494-495.

9. Palacios E, Valvassori G. Branchial cleft cyst. Ear Nose Thorat J 2001 May;80(5):302.

10. Ryu CW, Lee JH, Lee HK, Lee DH, Choi CG, Kim SJ. Clinical usefulness of multidetector CT fistulography of branchial cleft fistula. Clin Imaging 2006 Sep-Oct;30(5):339-342.

11. Francisco C, Agaton B, Cosmay GE. Diagnosis and treatment of branchial cleft cysts and fistulae. A retrospective study of 183 patients. Int J Oral Maxillofac Surg 1996 Dec;25(6): 449-452.

12. Bailey H. Branchial cysts and other essays on surgical subjects in the faciocervical region. London: Lewis; 1929. 